\title{
GENETIC DIVERSITY ASSESSMENT OF RICE (Oryza sativa L.) GERMPLASM USING SSR MARKERS
}

\author{
Ahasanul Hoque ${ }^{1^{*}}$, Shamsun Nahar Begum² and Lutful Hassan ${ }^{1}$ \\ 1Department of Genetics and Plant Breeding, Bangladesh Agricultural University, \\ Mymensingh- 2202, Bangladesh; ${ }^{2}$ Plant Breeding division, Bangladesh Institute of \\ Nuclear Agriculture, Mymensingh- 2202, Bangladesh
}

*Corresponding author: Ahasanul Hoque, E-mail: ahasanul102@bau.edu.bd

\section{ARTICLE INFO}

ABSTRACT

\section{Received}

17.11.2014

Accepted

15.12.2014

Online

27.12.2014

Key words:

Rice

Diversity

PIC

SSR marker
Diversity at molecular level among thirty rice genotypes, selected based on earliness and morphometric diversity was evaluated through five SSR markers associated with days to heading. Three primers viz., RM147, RM167 and RM215 showed polymorphism for growth duration related traits. A total of 17 alleles were detected among the 30 rice genotypes with an average of 5.66 alleles per locus. Polymorphism Information Content (PIC) ranged from 0.356 to 0.798 with an average of 0.543 . A dendrogram based on total microsatellite polymorphism grouped 30 genotypes into four major clusters at 0.39 similarity coefficient differentiating early maturing genotypes from others. This information about the genetic diversity will be very useful for proper identification and selection of appropriate parents for future breeding programs, including gene mapping. The results also showed that microsatellite markers associated to genes or QTLs controlling growth duration properties are suitable tools for marker assisted selection (MAS) to select rice lines with short growth duration.

To cite this article: A Hoque, SN Begum and L Hassan, 2014. Genetic diversity assessment of rice (Oryza sativa L.) germplasm using SSR markers. Res. Agric., Livest. Fish. 1(1): 37-46.

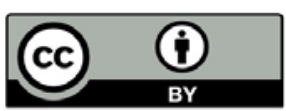

This article is an open access article licensed under the terms of the Creative Commons Attribution License.

www.agroaid-bd.org/ralf, e-mail: editor.ralf@gmail.com 


\section{INTRODUCTION}

Rice (Oryza sativa L.) is an important food crop which supplies staple food for nearly $50 \%$ of the global population (FAO, 2011; Garris et al., 2005). Among the most cultivated cereals in the world, rice ranks as second to wheat (Abodolereza and Racionzer, 2009). It is the basis of food security and is intimately associated with culture and customs of Bangladesh. Bangladesh is the fourth largest producer and consumer of rice in the world (FAO, 2011), with annual production of 33.54 million metric tons in an area of 11.52 million hectares of land (BBS, 2012). Bangladesh is an over populated country where peoples depend mainly on rice for their daily requirement. Net cultivable land of the country is 9.23 million hectares, total cropped area is 14.94 million hectares and cropping intensity is $191 \%$ (BBS, 2012). The demand of rice is constantly increasing in Bangladesh with nearly three million people are being added each year to the total population of the country (Chowdhury, 2009). To meet the food demand of the growing population and to achieve food security, the present production level need to be increased. For a successful breeding program, germplasm evaluation is a pre-requisite on which the future actions are taken. The importance of germplasm collection depends not only on the number of accessions it possesses, but also on genetic diversity present within those accessions.

Molecular marker technology provides information that can help to define the distinctiveness of germplasm and their ranking according to the number of close relatives and their phylogenetic position. Several molecular markers viz., RFLP (Becker et al., 1995), RAPD (Tingey and Deltufo, 1993), SSRs (Levinson and Gutman, 1987), ISSRs (Albani and Wilkinson, 1998; Blair et al., 1999), AFLP (Mackill et al., 1996; Zhu et al., 1998) and SNPs (Vieux, et al., 2002) are presently available to assess the diversity at molecular level. Simple sequence repeat (SSR) markers or microsatellites are tandem repeats interspersed throughout the genome and can be amplified using primers that flank these regions (Giovannoni et al., 1991). SSRs are able to identify the nature of the locus (homozygous or heterozygous condition) and have the advantage of being inexpensive, simple, rapid and only requiring small amount of DNA, may also be useful for the rapid screening of rice germplasm. Therefore present study was undertaken to assess genetic diversity of thirty rice germplasm using SSR markers.

\section{MATERIALS AND METHODS}

\section{Plant Materials}

Thirty rice genotypes were used for this study. Among them twenty seven rice accessions were collected from germplasm collection of Department of Genetics \& Plant Breeding, Bangladesh Agricultural University, Mymensingh and other three commercial varieties as check were collected from Bangladesh Rice Research Institute (BRRI), Gazipur. The studied genotypes were collected on the basis of morphological diversity and earliness behavior. The details of the plant materials used in this study was described by Hoque (2013) presented in Table 1.

\section{Genomic DNA Extraction}

DNA was extracted from leaf of 25 days old seedlings according to the modified CTAB method (Saghai-Maroof et al., 1984). DNA quality was checked by electrophoresis in an agarose gel and quantification was accomplished using spectrophotometer.

\section{Microsatellite Markers and PCR Amplification}

Initially five SSR markers were selected on the basis of their association with the trait days to heading (Table 2). DNA samples were amplified in $10 \mu \mathrm{l}$ reaction volumes containing of $2 \mu \mathrm{l}$

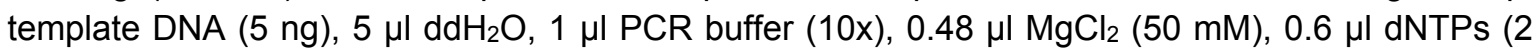


$\mathrm{mM}), 0.4 \mu \mathrm{l}$ of each primer (60 ng) and $0.12 \mu \mathrm{l}$ of Taq DNA Polymerase $(5 \mathrm{U} / \mu \mathrm{l})$. PCR was carried out in a thermal cycler (Perkin-Elmer-Gene Amp PCR System 9700, USA) to the cycle profile: Initial denaturation at $94^{\circ} \mathrm{C}$ for $4 \mathrm{~min}, 40$ cycles of 1 min denaturation at $94^{\circ} \mathrm{C}, 30 \mathrm{sec}$ annealing at $55^{\circ} \mathrm{C}$ or $61^{\circ} \mathrm{C}$ (depending on the marker used) and $1 \mathrm{~min}$ extension at $72^{\circ} \mathrm{C}$, and then $4 \mathrm{~min}$ at $72^{\circ} \mathrm{C}$ for the final extension.

\section{Electrophoresis}

PCR products were subjected to vertical electrophoresis (BioRad Sequi-Gen()) and 6\% polyacrylamide gel containing urea and separated from each other. The gels were stained with silver nitrate method (Bassam et al., 1991) and scanned. All experiments were performed in the Biotechnology Laboratory of the Bangladesh Institute of Nuclear Agriculture (BINA), Mymensingh.

Table 1. Details of the studied rice genotypes

\begin{tabular}{|c|c|c|c|c|c|}
\hline $\begin{array}{l}\text { Accession } \\
\text { No. }\end{array}$ & Designation & Source & $\begin{array}{l}\text { Days to } 50 \% \\
\text { Flowering }\end{array}$ & $\begin{array}{l}\text { Days to } \\
\text { Maturity }\end{array}$ & $\begin{array}{l}\text { Yield per } \\
\text { Plot (kg) }\end{array}$ \\
\hline G1 & BAU9-765-10 & GPB, BAU & 91 & 120 & 1.06 \\
\hline G4 & BAU15-934-76 & GPB, BAU & 109 & 142 & 0.28 \\
\hline G7 & BAU1-142-41 & GPB, BAU & 113 & 140 & 0.65 \\
\hline G8 & BAU5-423-29 & GPB, BAU & 105 & 133 & 0.30 \\
\hline G9 & BAU16-1192-7 & GPB, BAU & 95 & 122 & 0.57 \\
\hline G12 & BAU6-115-23 & GPB, BAU & 113 & 148 & 1.12 \\
\hline G18 & BAU10-671-102 & GPB, BAU & 94 & 125 & 0.50 \\
\hline G20 & BAU1-7 & GPB, BAU & 95 & 127 & 1.08 \\
\hline G21 & BAU7-437-8 & GPB, BAU & 93 & 127 & 0.57 \\
\hline G22 & BAU4-377-48 & GPB, BAU & 91 & 120 & 0.90 \\
\hline G24 & BAU94012-8-5-6-8-5-9-7-1 & GPB, BAU & 89 & 118 & 0.52 \\
\hline G25 & BAU94012-4-4-7-7-6-1-5-9 & GPB, BAU & 89 & 121 & 0.57 \\
\hline G27 & BAU94012-8-2-7-5-1-6-5-7 & GPB, BAU & 90 & 120 & 0.37 \\
\hline G28 & BAU94026-6-2-4-7-8-6-9-5 & GPB, BAU & 78 & 104 & 1.00 \\
\hline G29 & BAU94026-6-3-4-3-2-5-7-8 & GPB, BAU & 91 & 124 & 0.58 \\
\hline G33 & BAU94026-6-3-4-3-2-5-7-6 & GPB, BAU & 85 & 119 & 0.38 \\
\hline G34 & BAU92089-5-3-4-2-6-1-6-4 & GPB, BAU & 79 & 107 & 0.81 \\
\hline G37 & BAU94026-6-4-5-3-7-2-3-5 & GPB, BAU & 90 & 123 & 0.42 \\
\hline G39 & BAU6201-8-4-5-2-2-4-8-3 & GPB, BAU & 94 & 128 & 0.50 \\
\hline G42 & BR6017-3-1-1-3 & BRRI, Gazipur & 91 & 123 & 0.76 \\
\hline G45 & BR4839-17-5-2-2HR5 & BRRI, Gazipur & 92 & 126 & 0.60 \\
\hline G46 & $\mathrm{BR}(\mathrm{BE}) 6158-\mathrm{RWBC}-7-11$ & BRRI, Gazipur & 100 & 129 & 0.51 \\
\hline G48 & BR6017-3-3-4-1 & BRRI, Gazipur & 93 & 124 & 0.34 \\
\hline G49 & IR68926-61-2R & $\begin{array}{l}\text { IRRI, } \\
\text { Philippines }\end{array}$ & 75 & 105 & 0.80 \\
\hline G50 & IR58082-126-1-2R & $\begin{array}{l}\text { IRRI, } \\
\text { Philippines }\end{array}$ & 81 & 110 & 0.93 \\
\hline G53 & IR72 & $\begin{array}{l}\text { IRRI, } \\
\text { Philippines }\end{array}$ & 90 & 120 & 0.57 \\
\hline G54 & BRRI dhan 48 & BRRI, Gazipur & 81 & 110 & 1.01 \\
\hline G55 & BRRI dhan 27 & BRRI, Gazipur & 85 & 115 & 0.79 \\
\hline G56 & BR 26 & BRRI, Gazipur & 85 & 115 & 0.76 \\
\hline G59 & IR54 & $\begin{array}{l}\text { IRRI, } \\
\text { Philippines }\end{array}$ & 93 & 128 & 0.44 \\
\hline
\end{tabular}

Note: GPB= Department of Genetics and Plant Breeding, BAU= Bangladesh Agricultural University, BRRI= Bangladesh Rice Research Institute, IRRI= International Rice Research Institute 


\section{Data Analysis}

The size of most intensely amplified fragments was determined by comparing the migration distance of amplified fragments relative to the molecular weight of known size markers, 20 base pairs (bp) DNA ladder using Alpha-Ease FC 5.0 software (Alpha Innotech, USA). The number of alleles per locus, major allele frequency, gene diversity, PIC and Nei's genetic identity and genetic distance values were calculated using PowerMarker version 3.25 (Liu \& Muse, 2005). All the genotypes were scored for the presence or absence of the SSR bands throughout all 30 genotypes and the data were exported to binary data for the presence (1) or absence (0) or as a missing observation for further analysis with NTSYS-pc version 2.2 (Rohif, 2002). NTSYS-pc was used to construct a UPGMA (Unweighted Pair Group Method with Arithmetic Averages) dendrogram showing the distance-based interrelationship among the genotypes.

Table 2. SSR primers used in the present study for diversity analysis

\begin{tabular}{|c|c|c|c|c|}
\hline Locus & Primers & Repeat motif & AT & PS \\
\hline RM 47 & $\begin{array}{l}\text { 5' ACTCCACTCCACTCCCCAC } 3 \\
\text { 3'GTCAGCAGGTCGGACGTC5' }\end{array}$ & $(\mathrm{AG}) 7(\mathrm{AG}) 11$ & 55 & 229 \\
\hline RM 147 & $\begin{array}{l}\text { 5'TACGGCTTCGGCGGCTGATTCC3' } \\
\text { 3'CCCCCGAATCCCATCGAAACCC5' }\end{array}$ & (TTCC)5(GGT)5 & 55 & 97 \\
\hline RM167 & $\begin{array}{l}\text { 5'GATCCAGCGTGAGGAACACGT3' } \\
\text { 3'AGTCCGACCACAAGGTGCGTTGTC5' }\end{array}$ & $(\mathrm{GA}) 16$ & $55-60$ & 128 \\
\hline RM 202 & $\begin{array}{l}\text { 5'CAGATTGGAGATGAAGTCCTCC3' } \\
\text { 3'CCAGCAAGCATGTCAATGTA5' }\end{array}$ & (CT)30 & 55 & 189 \\
\hline RM 215 & $\begin{array}{l}\text { 5'CAAAATGGAGCAGCAAGAGC3' } \\
\text { 3'TGAGCACCTCCTTCTCTGTAG5' }\end{array}$ & (CT)16 & 55 & 148 \\
\hline
\end{tabular}

$\mathrm{AT}=$ Annealing temperature, $\mathrm{PS}=$ Product Size

Table 3. Details of polymorphic SSR markers

\begin{tabular}{|llllllll|}
\hline Marker & $\begin{array}{l}\text { Chrom. } \\
\text { No. }\end{array}$ & RM $^{*}$ & $\begin{array}{l}\text { No. of } \\
\text { allele }\end{array}$ & Frequency & $\begin{array}{l}\text { Size range } \\
\text { (bp) }\end{array}$ & Diversity & PIC \\
\hline RM147 & 10 & $(\mathrm{TTCC}) 5(\mathrm{GGT}) 5$ & 7 & 0.70 & $76-100$ & 0.49 & 0.476 \\
$\mathrm{RM} 167$ & 11 & $(\mathrm{GA}) 16$ & 8 & 0.30 & $118-145$ & 0.82 & 0.798 \\
RM215 & 9 & $(\mathrm{CT}) 16$ & 2 & 0.63 & $147-152$ & 0.46 & 0.356 \\
Mean & & & 5.66 & 0.54 & & 0.59 & 0.543 \\
\hline
\end{tabular}

$\mathrm{PIC}=$ polymorphism information content, Chrom.=Chromosome and $\mathrm{RM}^{*}=$ repeat motif. Motif of the SSR markers, position and number of repeats as previously published (http://www.gramene.org). 
Table 4. Nei's coefficients of similarity among 30 rice genotypes

\begin{tabular}{|c|c|c|c|c|c|c|c|c|c|c|c|c|c|c|c|c|c|c|c|c|c|c|c|c|c|c|c|c|c|c|}
\hline & G50 & G21 & G59 & G28 & G33 & G49 & G34 & G54 & G48 & G53 & G46 & G27 & G45 & G12 & G4 & G20 & G55 & G29 & G25 & G7 & G9 & G39 & G8 & G56 & G42 & G24 & G37 & G1 & G18 & G22 \\
\hline G50 & 1.00 & & & & & & & & & & & & & & & & & & & & & & & & & & & & & \\
\hline G21 & 0.67 & 1.00 & & & & & & & & & & & & & & & & & & & & & & & & & & & & \\
\hline G59 & 0.33 & 0.00 & 1.00 & & & & & & & & & & & & & & & & & & & & & & & & & & & \\
\hline G28 & 0.33 & 0.33 & 0.33 & 1.00 & & & & & & & & & & & & & & & & & & & & & & & & & & \\
\hline G33 & 0.67 & 1.00 & 0.00 & 0.33 & 1.00 & & & & & & & & & & & & & & & & & & & & & & & & & \\
\hline G49 & 0.33 & 0.33 & 0.00 & 0.33 & 0.33 & 1.00 & & & & & & & & & & & & & & & & & & & & & & & & \\
\hline G34 & 0.33 & 0.33 & 0.00 & 0.67 & 0.33 & 0.67 & 1.00 & & & & & & & & & & & & & & & & & & & & & & & \\
\hline G54 & 0.33 & 0.33 & 0.33 & 0.67 & 0.33 & 0.33 & 0.33 & 1.00 & & & & & & & & & & & & & & & & & & & & & & \\
\hline G48 & 0.33 & 0.00 & 0.67 & 0.00 & 0.00 & 0.33 & 0.33 & 0.00 & 1.00 & & & & & & & & & & & & & & & & & & & & & \\
\hline G53 & 0.67 & 0.33 & 0.33 & 0.33 & 0.33 & 0.67 & 0.67 & 0.33 & 0.67 & 1.00 & & & & & & & & & & & & & & & & & & & & \\
\hline G46 & 0.67 & 0.33 & 0.33 & 0.33 & 0.33 & 0.67 & 0.67 & 0.33 & 0.67 & 1.00 & 1.00 & & & & & & & & & & & & & & & & & & & \\
\hline G27 & 1.00 & 0.67 & 0.33 & 0.33 & 0.67 & 0.33 & 0.33 & 0.33 & 0.33 & 0.67 & 0.67 & 1.00 & & & & & & & & & & & & & & & & & & \\
\hline G45 & 0.67 & 0.33 & 0.33 & 0.33 & 0.33 & 0.67 & 0.67 & 0.33 & 0.67 & 1.00 & 1.00 & 0.67 & 1.00 & & & & & & & & & & & & & & & & & \\
\hline G12 & 0.00 & 0.00 & 0.67 & 0.33 & 0.00 & 0.00 & 0.00 & 0.33 & 0.33 & 0.00 & 0.00 & 0.00 & 0.00 & 1.00 & & & & & & & & & & & & & & & & \\
\hline G4 & 0.67 & 0.33 & 0.33 & 0.33 & 0.33 & 0.33 & 0.33 & 0.33 & 0.33 & 0.67 & 0.67 & 0.67 & 0.67 & 0.00 & 1.00 & & & & & & & & & & & & & & & \\
\hline G20 & 0.33 & 0.00 & 0.67 & 0.00 & 0.00 & 0.00 & 0.00 & 0.00 & 0.67 & 0.33 & 0.33 & 0.33 & 0.33 & 0.33 & 0.67 & 1.00 & & & & & & & & & & & & & & \\
\hline G55 & 0.33 & 0.00 & 0.67 & 0.00 & 0.00 & 0.00 & 0.00 & 0.00 & 0.67 & 0.33 & 0.33 & 0.33 & 0.33 & 0.33 & 0.33 & 0.67 & 1.00 & & & & & & & & & & & & & \\
\hline G29 & 0.67 & 0.33 & 0.33 & 0.33 & 0.33 & 0.33 & 0.33 & 0.33 & 0.33 & 0.67 & 0.67 & 0.67 & 0.67 & 0.00 & 0.67 & 0.33 & 0.67 & 1.00 & & & & & & & & & & & & \\
\hline G25 & 0.67 & 0.33 & 0.33 & 0.33 & 0.33 & 0.33 & 0.33 & 0.33 & 0.33 & 0.67 & 0.67 & 0.67 & 0.67 & 0.00 & 0.67 & 0.33 & 0.67 & 1.00 & 1.00 & & & & & & & & & & & \\
\hline G7 & 0.67 & 0.33 & 0.33 & 0.33 & 0.33 & 0.33 & 0.33 & 0.33 & 0.33 & 0.67 & 0.67 & 0.67 & 0.67 & 0.00 & 0.67 & 0.33 & 0.33 & 0.67 & 0.67 & 1.00 & & & & & & & & & & \\
\hline G9 & 0.00 & 0.00 & 0.33 & 0.00 & 0.00 & 0.00 & 0.00 & 0.00 & 0.33 & 0.00 & 0.00 & 0.00 & 0.00 & 0.33 & 0.00 & 0.33 & 0.33 & 0.00 & 0.00 & 0.00 & 1.00 & & & & & & & & & \\
\hline G39 & 0.33 & 0.00 & 0.67 & 0.00 & 0.00 & 0.00 & 0.00 & 0.00 & 0.67 & 0.33 & 0.33 & 0.33 & 0.33 & 0.33 & 0.33 & 0.67 & 0.67 & 0.33 & 0.33 & 0.33 & 0.67 & 1.00 & & & & & & & & \\
\hline G8 & 0.67 & 0.33 & 0.33 & 0.33 & 0.33 & 0.33 & 0.33 & 0.33 & 0.33 & 0.67 & 0.67 & 0.67 & 0.67 & 0.00 & 0.67 & 0.33 & 0.33 & 0.67 & 0.67 & 0.67 & 0.00 & 0.33 & 1.00 & & & & & & & \\
\hline G56 & 0.33 & 0.00 & 0.67 & 0.00 & 0.00 & 0.00 & 0.00 & 0.00 & 0.67 & 0.33 & 0.33 & 0.33 & 0.33 & 0.33 & 0.33 & 0.67 & 1.00 & 0.67 & 0.67 & 0.33 & 0.33 & 0.67 & 0.33 & 1.00 & & & & & & \\
\hline G42 & 1.00 & 0.67 & 0.33 & 0.33 & 0.67 & 0.33 & 0.33 & 0.33 & 0.33 & 0.67 & 0.67 & 1.00 & 0.67 & 0.00 & 0.67 & 0.33 & 0.33 & 0.67 & 0.67 & 0.67 & 0.00 & 0.33 & 0.67 & 0.33 & 1.00 & & & & & \\
\hline G24 & 0.67 & 0.33 & 0.67 & 0.00 & 0.33 & 0.00 & 0.00 & 0.00 & 0.67 & 0.33 & 0.33 & 0.67 & 0.33 & 0.33 & 0.33 & 0.67 & 0.67 & 0.33 & 0.33 & 0.33 & 0.33 & 0.67 & 0.33 & 0.67 & 0.67 & 1.00 & & & & \\
\hline G37 & 1.00 & 0.67 & 0.33 & 0.33 & 0.67 & 0.33 & 0.33 & 0.33 & 0.33 & 0.67 & 0.67 & 1.00 & 0.67 & 0.00 & 0.67 & 0.33 & 0.33 & 0.67 & 0.67 & 0.67 & 0.00 & 0.33 & 0.67 & 0.33 & 1.00 & 0.67 & 1.00 & & & \\
\hline G1 & 0.33 & 0.00 & 0.67 & 0.00 & 0.00 & 0.00 & 0.00 & 0.00 & 0.67 & 0.33 & 0.33 & 0.33 & 0.33 & 0.33 & 0.33 & 0.67 & 0.67 & 0.33 & 0.33 & 0.67 & 0.33 & 0.67 & 0.33 & 0.67 & 0.33 & 0.67 & 0.33 & 1.00 & & \\
\hline G18 & 1.00 & 0.67 & 0.33 & 0.33 & 0.67 & 0.33 & 0.33 & 0.33 & 0.33 & 0.67 & 0.67 & 1.00 & 0.67 & 0.00 & 0.67 & 0.33 & 0.33 & 0.67 & 0.67 & 0.67 & 0.00 & 0.33 & 0.67 & 0.33 & 1.00 & 0.67 & 1.00 & 0.33 & 1.00 & \\
\hline G22 & 0.33 & 0.33 & 0.33 & 0.00 & 0.33 & 0.00 & 0.00 & 0.00 & 0.33 & 0.00 & 0.00 & 0.33 & 0.00 & 0.33 & 0.00 & 0.33 & 0.33 & 0.00 & 0.00 & 0.00 & 0.67 & 0.33 & 0.00 & 0.33 & 0.33 & 0.67 & 0.33 & 0.33 & 0.33 & 1.00 \\
\hline
\end{tabular}

www.agroaid-bd.org/ralf

41 


\section{RESULTS AND DISCUSSION}

\section{Overall allelic diversity}

Among the five SSR motifs used in the present study three SSR motifs were polymorphic (Fig 1) which produced varying number of alleles with different size ranges (Table 3 ). A total of 17 alleles were detected among the 30 rice genotypes with an average of 5.66 alleles per locus. The number of alleles per locus ranged from 2 in RM215 to 8 in RM167. This value was lower to the average of 5.89 per microsatellite locus reported by Lapitan et al., (2007), while it was higher than the average of 4.23 alleles per locus reported by Ghneim et al., (2008) for Venezuelan rice cultivars and the average of 3 alleles per locus reported by Kibria et al., (2009) using microsatellite markers linked to genes controlling rice grains aroma. Furthermore, the average number of alleles per locus obtained in the present study was smaller than that reported in previous studies. For example Kuroda et al., (2007) reported an average of 9.28 alleles per locus over 7 SSR loci and Shefatur Rahman et al., (2009) who recorded 6.33 alleles per locus using a small set of three SSR markers on 34 varieties. The overall size of amplified products ranged from $76 \mathrm{bp}$ in locus RM147 to $152 \mathrm{bp}$ in locus RM215. On average, $54 \%$ of the 30 rice genotypes shared a common major allele ranging from $30 \%$ (RM167) to 70\% (RM147) common allele at each locus. Sajib et al., (2012) also found that $56 \%$ of the 12 rice accessions shared a common major allele at any given locus ranging from $41 \%$ (RM163, RM590, and RM413) to 91\% (RM510) common allele at each locus. A moderate level of diversity exists among 3 loci studied across 30 rice accessions, ranged from 0.46 to 0.82 with an average of 0.59 . Sajib et al., (2012) also found a moderate level of diversity exists among 9 loci studied across 12 rice accessions, ranged from 0.15 to 0.75 with an average of 0.54 .

\section{PIC value}

Polymorphism information content (PIC) value is a reflection of allele diversity and frequency among the varieties. PIC value of each marker can be evaluated on the basis of its alleles and it varied greatly for all the SSR loci tested. In the present study, the level of polymorphism among the 30 genotypes was evaluated by calculating PIC values for each of the 3 SSR loci. The PIC values ranged from 0.356 (RM215) to 0.798 (RM167) with an average of 0.543 per locus (Table 3 ). The early reports on the PIC values ranged from 0.24 to 0.92 with an average of 0.61 (Jain et al., 2004), 0.19 to 0.90 with an average of 0.75 (Borba et al., 2009), which is markedly higher than that of the present study. Upadhyay et al., (2011) also reported the average PIC value of 0.78 which is higher than the result in this study. The result revealed that markers RM167 would be best in screening 30 rice genotypes due to its highest PIC value followed by RM147 and RM215.

\section{Similarity matrix}

The SSR-derived data were subjected to calculate the genetic similarity (Table 4). The similarly matrix was used to determine the level of relatedness among the genotypes studied. Pair-wise estimates of similarity ranged from 0.00 to 1.00 and the average similarity among all 30 genotypes was 0.39. Saini and colleagues (2004) also reported almost similar values of similarity co-efficient among 18 basmati and non-basmati varieties using molecular markers. Likewise, similarity coefficients ranging from 0.24 to 0.92 were observed in eight basmati accessions originating from Pakistan and one solitary indica accession for the SSR analysis by Jayamani et al., (2007). Siwach et al., (2004) also observed higher level of similarity ranging from 0.67 to 0.91 among basmati and nonbasmati long-grain indica rice varieties using microsatellite markers. One of the reasons for this high level of similarity recorded by the present and previous studies could be due to intra-specific variation in the germplasm used.

The pairwise genetic similarity indices indicated that there were $100 \%$ genetic similarity among the genotypes G18, G27, G42 and G50; G45, G46 and G53; G21 and G33; G25 and G29; G55 
and G56. Genotypes having 100\% similarity with each other were found as duplicate considering the studied loci. Sajib et al., (2012) also found Deepa and Patnai-23 as duplicate. Again findings of that study revealed that there was no similarity (0\%) of genotype G20 with G21, G28, G33, G49, G34 and G54; genotype G55 with G21, G28, G33, G49, G34 and G54 and so on.
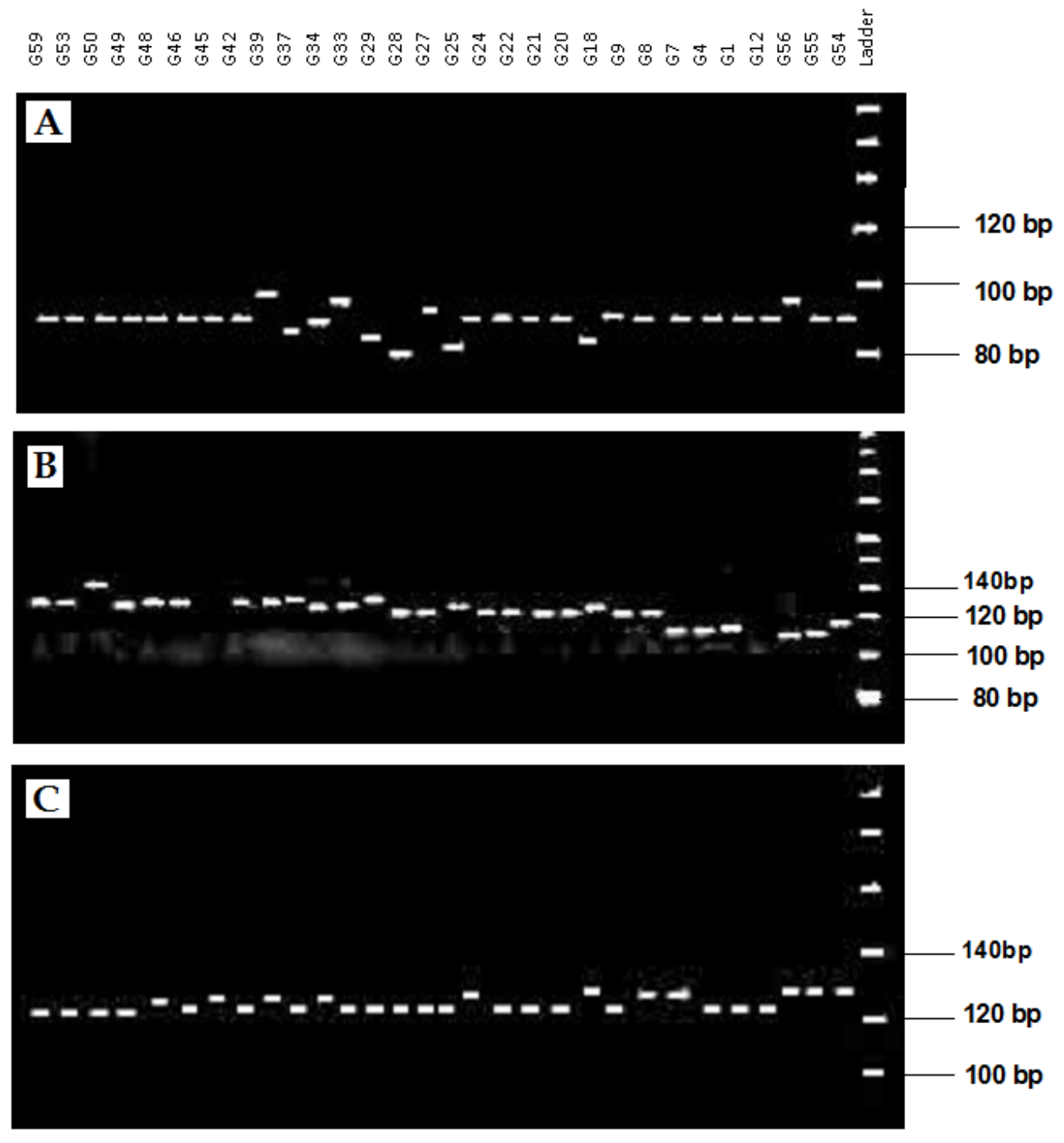

Fig 1. SSR profiles of 30 rice genotypes including 3check varieties using primer

RM 147 (A), RM 167 (B) and RM 215 (C)

\section{Cluster analysis}

Cluster analysis was performed using the UPGMA method to group the studied genotypes based on similarity coefficient. Four clusters were formed at genetic similarity level of 0.21 0.0.41(Fig 2). Cluster I, II, III and IV contained 15, 4, 10 and 1 genotypes respectively. The days to maturity of the genotypes of cluster I ranged from 110 to 142 days indicating mixture of short, intermediate and long duration genotypes. Cluster II comprised of 3 accessions and one check variety viz., BRRI dhan 48 (G54). All genotypes in this group were short duration with good yielding capability. 


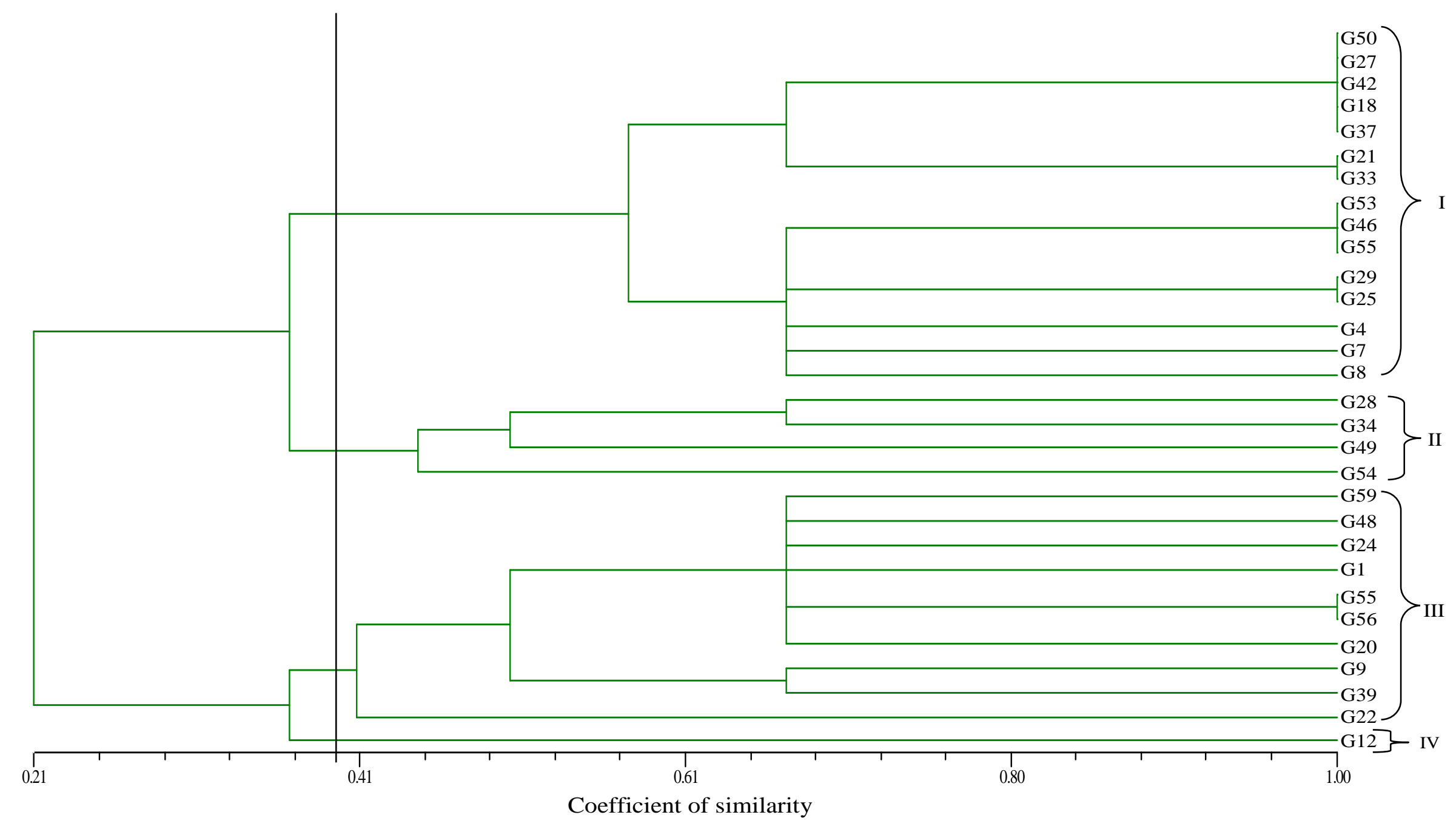

Fig 2. UPGMA cluster dendrogram showing the genetic relationship among 30 rice genotypes 
Cluster III comprised of 8 accessions and 2 check varieties viz. BRRI dhan 27 (G55) and BR 26 (G56). All genotypes in this group were classified as medium duration with good tillering ability. Cluster IV comprised of only accession G12 having the highest growth duration (148 days). The results of cluster analysis revealed that the short duration genotypes were well classified from other genotypes. The result of this study was supported by the findings of Pervaiz et al., (2010). Tabkhkar et al., (2012) also grouped 48 rice genotypes with SSR markers in four main clusters and the dendrogram revealed that the landrace cultivars with good cooking and eating quality (based on Iranian taste) were well separated from others. In this study, the larger range of similarity values for genotypes revealed by microsatellite markers provides greater confidence for the assessments of genetic diversity and relationships, which can be used in future breeding programs. With the aid of microsatellite makers and clustering data, different distantly related rice genotypes may be combined by intercrossing genotypes, for instance, short duration rice genotypes with long duration rice genotypes from different clusters to get hybrid varieties with highest heterosis and to screen out desirable genotypes from segregating generations.

\section{CONCLUSION}

Results of this research indicated that the use of microsatellite markers associated with days to heading can differentiate rice accessions from each other for the traits related to growth duration. The findings provide a basement for the breeders to select diversified parents to exploit heterosis in hybrid progenies for growth duration. The results also served as a sound basis for duplicate sorting of the morphologically close accessions. For better precision of diversity and duplication among accessions more SSR markers could be employed for further research. Overall these results could be useful for monitoring purity, accessions identification and management.

\section{REFERENCES}

1. Abodolereza A and P Racionzer, 2009. Food Outlook: Global market analysis. 23-27.

2. Albani MC and MJ Wilkinson, 1998. Inter simple sequence repeat polymerase chain reaction for the detection of somaclonal variation. Plant Breeding, 117: 573-575.

3. Bassam BJ, G Caetano-Anollés and PM Gresshoff, 1991. Fast and sensitive silver staining of DNA in polyacrylamide gels. Analytical biochemistry, 196: 80-83.

4. BBS, 2012. The year book of agricultural statistics of Bangladesh. Statistics Division, Ministry of Planning, Government of Peoples Republic, Bangladesh, Dhaka, pp.123-127.

5. Becker J, P Vos, M Kuiper, F Salamini and M Heun, 1995. Combined mapping of AFLP and RFLP markers in barley. Molecular and General Genetics, 249: 65-73.

6. Blair MW, O Panaud and SR McCouch, 1999. Inter-simple sequence repeat (ISSR) amplification for analysis of microsatellite motif frequency and fingerprinting in rice (Oryza sativa L.). Theoretical and Applied Genetics, 98: 780-792.

7. Borba TCO, RPV Brondani, PHN Rangel and C Brondani, 2009. Microsatellite marker-mediated analysis of the EMBRAPA rice core collection genetic diversity. Genetica, 137: 293-304.

8. Chowdhury MR, 2011. The Population challenge facing Bangladesh. Public Journal of Social Sciences, 11: 1-6.

9. FAO, 2011. Food and agricultural commodities production. Food and Agriculture Organization of the United Nations.Garris, AJ, TH Tai, J Coburn, S Kresovich and S McCouch, 2005. Genetic structure and diversity in Oryza sativa L. Genetics, 169: 1631-1638.

10. Ghneim T, D Posso, I Perez, G Torrealba, AJ Pieters, CP Martinez and JM Tohme, 2008. Assessment of genetic diversity in Venezuelan rice cultivars using simple sequence repeats markers. Electronic Journal of Biotechnology, 11: 1-14. 
11. Giovannoni JJ, RA Wing, MW Ganal and S Tanksley, 1991. Isolation of molecular markers from specific chromosomal intervals using DNA pools from existing mapping populations. Nucleic Acids Research, 19: 6553-6558.

12. Hoque A, 2013. Morphophysiological and molecular characterization of rice (Oryza sativa L.) advanced breeding lines for earliness. MS thesis, Bangladesh Agricultural University, Mymensingh, Bangladesh.

13. Jain S, RK Jain and SR McCouch, 2004. Genetic analysis of Indian aromatic and quality rice (Oryza sativa L.) germplasm using panels of fluorescently-labeled microsatellite markers. Theoretical and. Applied Genetics, 109: 965-977.

14. Jayamani P, S Negrao, M Martins, B Macas and MM Oiveira, 2007. Genetic relatedness of Portuguese rice accessions from diverse origins as assessed by microsatellite markers. Crop Science, 47: 879-886.

15. Kibria K, F Nur, SN Begum, MM Islam, SK Paul, KS Rahman, and SMM Azam, 2009. Molecular marker based genetic diversity analysis in aromatic rice genotypes using SSR and RAPD markers. International Journal of Sustainable Crop production, 4: 23-34.

16. Kuroda, Y, YI Sato, C Bounphanousay, Y Kono and K Tanaka, 2007. Genetic structure of three Oryza AA genome species (O. rufipogon, $O$. nivara and $O$. sativa) as assessed by SSR analysis on the Vientiane Plain of Laos. Conservation Genetics, 8: 149-158.

17. Lapitan VC, DS Brar, T Abe and ED Redona, 2007. Assesment of genetic diversity of Philippine rice cultivars carrying good quality traits using SSR markers. Breeding Science, 57: 263-270.

18. Levinson, $G$ and GA Gutman, 1987. Slipped-strand mis-pairing: a major mechanism of DNA sequence evolution. Molecular Biology and Evolution, 4: 203-221.

19. Liu K and SV Muse, 2005. PowerMarker: an intregrated analysis environment for genetic marker analysis. Bioinformatics, 21: 2128-2129.

20. Mackill DJ, Z Zhang, ED Redona and PM Colowit, 1996. Level of polymorphism and genetic mapping of AFLP markers in rice. Genome, 39: 969-977.

21. Pervaiz ZH, MA Rabbani, I Khaliq, SR Pearce and SA Malik, 2010. Genetic diversity associated with agronomic traits using microsatellite markers in Pakistani rice landraces. Electronic Journal of Biotechnology, 13: 4-5.

22. Rohif FJ, 2002. NTSYS-pc: Numerical taxonomy and multivariate analysis system (Ed. 2.2), Department of Ecology and Evolution, State University of NY, Stony Brook.

23. Saghai-Maroof MA, KM Soliman, RA Jorgensen and RW Allard, 1984. Ribosomal DNA spacer-length polymorphisms in barley: Mendelian inheritance, chromosomal location, and population dynamics. Proceedings of the National Academy of Sciences, 81: 8014-8018.

24. Sajib AM, MM Hossain, ATMJ Mosnaz, H Hossain, MM Islam, MS Ali and SH Prodhan, 2012. SSR marker-based molecular characterization and genetic diversity analysis of aromatic landraces of rice (Oryza sativa L.). Journal of Bioscience and Biotechnology, 1: 107-116.

25. Shefatur RM, MM Rezwan, AM Samsul and L Rahman, 2009. DNA fingerprinting of rice (Oryza sativa L.) cultivars using microsatellite markers. Australian Journal of Crop Science, 3: 122-128.

26. Siwach P, S Jain, N Saini, VK Choudary and RK Jain, 2004. Allelic diversity among Basmati and non-Basmati long-grain indica rice varieties using microsatellite markers. Journal of Plant Biochemistry and Biotechnology, 13: 25-32.

27. Tabkhkar N, B Rabiei and A Sabouri, 2012. Genetic diversity of rice cultivars by microsatellite markers tightly linked to cooking and eating quality. Australian Journal of Crop Science, 6: 980-985.

28. Tingey SV and JP Deltufo, 1993. Genetic analysis with Random Amplified Polymorphic DNA. Plant Physiology, 101: 349-352.

29. Upadhyay P, VK Singh and CN Neeraja, 2011. Identification of genotype specific alleles and molecular diversity assessment of popular rice (Oryza sativa L.) varieties of India. International Journal of Plant Breeding and Genetics, 5: 130-140.

30. Vieux EF, PY Kwok and RD Miller, 2002. Primer design for PCR and sequencing in high-throughput analysis of SNPs. Biotechniques, 32: 28-30.

31. Zhu J, MD Gale, S Quarrie, MT Jackson and GJ Bryan, 1998. AFLP markers for the study of rice biodiversity. Theoretical and Applied Genetics, 96: 602-611. 